\title{
Erratum to: Correlation between otitis media and dental malocclusion in children
}

\author{
M. R. Giuca - E. Caputo - S. Nastasio - M. Pasini
}

Published online: 12 November 2014

(C) European Academy of Paediatric Dentistry 2014

Erratum to: Eur Arch Paediatr Dent (2011) 12:241-244

\section{DOI 10.1007/BF03262815}

The family names of the third and fourth authors were rendered incorrectly. The error is rectified here.

The online version of the original article can be found under doi:10.1007/BF03262815.

M. R. Giuca $(\square) \cdot$ E. Caputo · M. Pasini

Department of Surgery, Unit of Paediatric Dentistry,

University of Pisa, Via Roma 67, Pisa, PI 56100, Italy

e-mail: m.giuca@odont.med.unipi.it

S. Nastasio

Department of Paediatrics, University of Pisa, Pisa, Italy 